\title{
Cyanobacteria that Promote Plant Growth and Metabolites
}

\author{
Çiğdem KÜÇÜK*, Göksal SEZEN
}

Department of Biology, Faculty of Arts and Sciences, Harran University, 63000, Sanliurfa, Turkey

ORCID ID: Çiğdem KÜÇÜK: https://orcid.org/0000-0001-5688-5440; Göksal SEZEN: https://orcid.org/0000-0001-9054-851X

\begin{abstract}
Received: 26.06 .2019
Accepted: 02.07.2019

Published online: 20.12 .2019

Issue published: 20.12 .2019

Abstract: Cyanobacteria help to dissolve phosphate and minerals to increase plant production and soil fertility, and contribute to the biological nitrogen fixation. In addition, many cyanobacteria secrete elicitor molecules such as amino acids, proteins, polysaccharides, phytohormones, vitamins and carbohydrates to promote plant growth. Thus, they protect plants against biotic and abiotic stress. Cyanobacteria have antagonistic activity against many plant pathogen fungi. With the application of cyanobacteria as the biocontrol agent, the severity of the disease has decreased in many plants. In this review, the effects of metabolites secreted by cyanobacteria on plant growth and their effects on their use in agriculture are discussed.
\end{abstract}

Keywords: Cyanobacteria, elicitor molecules, biofertilizer, plant growth promotion.

\section{Bitki Gelişimini Teşvik Eden Siyanobakteriler ve Metabolitleri}

Öz: Siyanobakteriler, bitkisel üretimi ve toprak verimliliğini artırmak için fosfat ve mineral çözünmesine yardımcı olurlar, biyolojik azot fiksasyonuna katkıda bulunurlar. Ayrıca, birçok siyanobakteri, bitki gelişimini teşvik için aminoasit, protein, polisakkarit, fitohormon, vitamin, karbonhidrat gibi elisitör molekülleri salgilarlar. Böylece bitkileri biyotik ve abiyotik strese karşı korurlar. Siyanobakteriler birçok bitki patojeni fungusa karşı antagonistik aktivite göstermektedir. Biyokontrol etmeni olarak siyanobakterilerin uygulanması birçok bitkide hastalık şiddetini azaltmıştır. Bu derlemede, siyanobakteriler tarafından salgılanan metabolitlerin bitki gelişimi ve büyümesindeki rolleri, tarımda kullanımı üzerine etkilerine değinilmiştir.

Anahtar kelimeler: Siyanobakteri, elisitör moleküller, biyogübre, bitki gelişimini teşvik.

\section{Giriş}

Bitkilerle ilişkili olan farklı mikroorganizma gruplarının, bitkiler üzerinde yararlı etkilere sahip, metabolitler ürettiği açıklanmıştır (Berendsen, Pieterse, \& Bakker, 2012; Mendes, Garbeva, \& Raaijmakers, 2013). Patojenlerin bitkilerle olan zararlı etkileşimleri uzun yıllar boyunca bilinmekte olup; bitki büyümesini teşvik eden (PGPR) mikroorganizmalar ve bitki iletişimleri ile ilgili sinyalleri ortaya çıkarmak için çalışmalar son yıllarda hız kazanmıştır. PGPR mikroorganizmalarının, plazma zarı üzerindeki reseptör bölgelerine bağlanabilen ve genlerin aktivasyonuna neden olabilen, proteinlerin ve enzimlerin veya sekonder metabolitlerin sentezine yol açan sinyalleşme bileşiklerini serbest bıraktıkları bildirilmiştir (Hussain, Hamayun, \& Shah, 2013). Karbonhidrat, lipid, glikolipid veya glikoprotein grubuna ait olan fitokimyasal tepkiye dahil olan elisitörlerin ve sinyalleme bileşiklerinin birçoğu tanımlanmıştır (Yamaguchi \& Huffaker, 2011). Bu bileşiklerin bazıları, sprey şeklinde veya kök muamelesi olarak bitkilere uygulandığında glikosinolatlar, alkaloidler, polifenoller, flavonoidler, flavonoid glikozitler, saponinler terpenler, fitoaleksinler gibi bir dizi bitki fitokimyasalının birikiminde artışa neden olduğu tespit edilmiştir (Hussain et al., 2013; Misra \& Kaushik, 1989a; Rodriguez, Stella, Storni, Zulpa \& Zaccaro, 2006). $\mathrm{Bu}$ fitokimyasalların bitkileri biyotik ve abiyotik strese karşı koruma sağlamakta olup, direnç geliştirmelerine yardımcı oldukları belirlenmiştir (Shan, Yan, \& Xie, 2012; Sokolova, Akimova, \& Vaishlya, 2011). Bitkilerde fitokimyasal bileşimini arttırmak için elisitörlerin kullanımı ile ilgili çeşitli araştırmalar yapılmıştır. Örneğin; Briceno et al. (2012) ve Pan ve Liu (2011) çalışmalarında elmada antosiyanin, fenolik ve askorbik asit üretimi, mango ve patateslerde fitosterol ve taraksasterol ve ahudududaki flavonoidlerin arttığını tespit etmişlerdir. Elisitörlerle muamele edildiğinde karotenoidlerin, özellikle likopen ve ß-karoten seviyesinin, domateslerde arttığ1 (Singh, 2014), havuçlarda ise terpenler, özellikle terenler, limonen ve kariyofil içeriklerinde artış meydana geldiği araştırıcılar tarafından bildirilmiştir (Singh, 2014; Takaichi, Maoka, \& Mochimaru, 2009). Bu fitokimyasalların bitkilere uygulanan yararlı etkilerinin yanı sıra, terapötik olarak yüksek değere sahip oldukları açıklanmış; antioksidanlar, antikanserojen, antibakteriyel, antifungal, antiviral, antitrombotik, antienflamatuar, kan basıncını ve kan şekeri ile bağışıklığı destekleyici ve kolesterol düşürücü özelliklerinden dolayı sağlık üzerinde de etkili olabildikleri Yadav et al. (2017) tarafından açıklanmıştır. Böylece, fitokimyasalların geliştirilmesi, tarım endüstrisi için önemli ekonomik faydalara sahip olabilecek yeni bir araştırma alanı açmıştır. Bitki hastalıklarının laboratuvar, sera ve tarla koşullarında kontrol altına alınması için uyarılan direnç ile ilgili çalışmalar, AR-GE ürünlerinin ticarileştirilmesini sağlamış ve böylece üreticilere yeni nesil mikrobiyal gübreler veya ürün koruyucuları kazandırılmıştır.

Bitki gelişimini destekleyen mikroorganizmalar ilgili yapılan çalışmalar incelendiğinde üzerinde en çok araştırma yapılanların rizobakteriler, mikorizal mantarlar ve simbiyotik rhizobia olduğu tespit edilmiştir. Son zamanlarda yapılan araştırmalarda ise bitki gelişmesini teşvik eden bir başka mikroorganizma grubunun da siyanobakteriler olduğu görülmektedir (Mendes et al., 2013; Willis, Rodrigues, \& Harris, 2013). Son y1llarda 
yapılan araştırmalarda siyanobakteriler tarafından üretilen sinyaller ile konak bitkilerin gen ifadesini etkileyen veriler elde edilmiş, böylece bitkilerin fitokimyasal bileşimlerinde kalitatif ve kantitatif değişiklikler meydana geldiği tespit edilmiştir (Manjunath et al., 2010; Sing, Kumar, Rai, \& Singh, 2016; Yadav et al., 2017). Bu derlemede, siyanobakterilerin olası elisitör molekülleri ve siyanobakteriler tarafından bitkilerin gelişimleri üzerindeki rollerine değinilmiştir.

\section{Siyanobakteriler ve Önemleri}

Mavi-yeşil algler olarak da bilinen siyanobakteriler, oksijenli solunum yapan, fotosentetik prokaryotik organizmalar olarak tanımlanmıştır (Yadav et al., 2017). Bunlar, morfolojik ve gelişimsel olarak, değişik hücre tiplerine sahip olan, ipliksi formlara kadar ikili füzyon ile çoğalan, basit tek hücreli formlardan oluşan prokaryot canlı gruplarından biridir (Yadav et al., 2017). Siyanobakterilerin habitat olarak tatlı su, deniz ve karasal ortamları kullandıkları bilinmektedir. $\mathrm{Bu}$ yaşam ortamlarına ilave olarak kaplıca suları ve buzulları da habitat olarak kullanabildikleri çeşitli araştırmalar ile tespit edilmiştir (Nagarajan, Maruthanayagam, \& Sundararaman, 2011). Bitkilerle birlikteliklerinin yanı sıra, ağaç kabuğu üzerinde, yapraklar, kökler ve su altındaki alanların batık kökleri ve sapları üzerinde epifitik olarak gelişebilmektedirler (Aguiar et al., 2008; Boopathi, Balamurugan, Gopinath, \& Sundararaman, 2013). Siyanobakteriler, bitki partnerinin büyümesi için azot sağlarlar. Siyanobakterilerin, atmosferik azotu nitrogenaz enzimi ile amonyum formuna dönüştürebildikleri $\left(\mathrm{N}_{2}+8\right.$ $\mathrm{H}^{+}+8 \mathrm{e}^{-}+16 \mathrm{MgATP} \rightarrow 2 \mathrm{NH}_{3}+\mathrm{H} 2+16 \mathrm{MgADP}+16$ $\mathrm{Pi})$ ve bu olayda ATP'nin kullanıldığı açıklanmıştır (Magnuson, 2019).

Simbiyotik birliktelikteki bitki partneri ise, siyanobakteriye koruma ve beslenmeyi sağlayan özgün fiziko-kimyasal faktörlere sahip eşsiz bir yaşam alanı sunmaktadır. Başarılı simbiyozun başlatılmasının ve koordine edilmesi ortaklar arasındaki bir dizi düzenli sinyal alışverişine bağlıdır (Long, 2001; Mendes et al., 2013; Stam \& Kumar, 2010). Yapilan çalışmalar, siyanobakterilerin, konakçılarda gen ifadesini etkileyen sinyaller ürettiği ve konakçllardan gelen sinyalleri algılayarak, bunlara cevap verip ortaklığın oluşumunda çok önemli rol oynadığını göstermiştir (Yadav et al., 2017). Bitkilerde, çevresel değişiklikleri algılayan, patojen ve simbiyotik mikroorganizmaların ayırt edilmesinden sorumlu mekanizmalar bulunmaktadır (Mendes et al., 2013). Bu sinyallerin rhizobia tarafindan salınan nodül indükleyici faktörler (Nod faktörleri) ile fonksiyonel olarak benzer olduğu düşünülmektedir. Nod faktörleri kök korteksinde hücre bölünmesini uyararak yeni bir organ olan kök nodülü oluşumuna yol açtığı bildirilmiştir (Long, 2001).

Siyanobakterilerin likenlerde tallus morfojenezini etkilediği bilinmektedir (Singh et al., 2016). Likenler üzerinde yapılan çalışmalarda, belirli bir mantarın farklı siyanobakteriyel ortaklarla farklı morfolojiler ürettiğini ve farklı siyanobakteriyel suşlar tarafından farklı sinyaller salgılandığını göstermiştir (Singh, 2014).

Siyanobakterilerin ve özellikle bitkilerle simbiyotik ilişkiler oluşturanların karbonhidrat açısından zengin arabinogalaktan proteinleri saldıkları keşfedilmiştir. Bu proteinlerin sinyal molekülleri olarak hareket etmeleri, bitki büyümesi ve gelişiminin düzenlenmesinde önemli bir rol oynamadiğı tespit edilmiştir (Abdel-Raouf, AlHomaidan, \& Ibraheem, 2012). Siyanobakteriler tarafindan fitohormonların salgılanması, simbiyotik birlikteliğin oluşumu ile başlamaktadır (Sing et al., 2016). Yapılan çalışmalarda Anabaena-Azollae'nin azot bağlanması sırasında ürettikleri fitohormonlar tespit edilmiştir (Sokolova et al., 2011; Yadav et al., 2017). Üretilen fitohormonun sadece simbiyozu uyarmakla kalmadı $\breve{g}_{1}$, aynı zamanda konakçı bitkide bir dizi metabolik aktivitenin tetiklenmesine yardımcı olduğu tespit edilmiştir (Sokolova et al., 2011; Yadav et al., 2017).

\section{Bitkilerde Siyanobakteriyel Sinyaller}

Siyanobakteriler, biyolojik azot fiksasyonuna potansiyel katkıda bulunan, toprak verimliliğini ve ürün verimliliğini arttırmak için fosfatın çözünmesine ve mineral salınımına katkıda bulunan birçok tarım topraklarının önemli sakinleri olarak tanımlanmıştır (Singh, 2014). Siyanobakterin, bitki büyümesini desteklemek için sinyal molekülleri olarak işlev gören proteinler, vitaminler, karbonhidratlar, amino asitler, polisakkaritler ve fitohormonlar gibi çeşitli biyolojik olarak aktif maddeleri serbest bıraktığı bilinmektedir. İlgili bakterilerin ekili tarlalarda da bulundukları saptanmıştır. Bitki büyümesinde etkili baskın suşların saptanması bitkisel üretim açısından önemli bulunmuştur (Osman, El-Sheekh, El-Naggar, \& Gheda, 2010; Prasanna et al., 2009b).

Rizosfer için mikroorganizmaların bolluğu ve çeşitliliği önemlidir. Çoğu mikroorganizma için uygun bir niş sunmaktadır ve bu mikroorganizmaların metabolik aktiviteleri bitki gelişimi ile yakından ilişkilidir (Singh, 2014). Prasanna, Jaiswal, Nayak, Sood ve Kaushik (2009a), Hindistan'ın çeşitli bölgelerinden izole edilen pirinç rizosferindeki siyanobakterilerin bolluğunu ve cins olarak çeşitliliğini karakterize etmek için bir araştırma yapmışlardır. Araştırma sonucunda Nostoc sp. Vaucher ex Bornet \& Flahault ve Anabaena sp. Bory ex Bornet \& Flahault cinslerine ait siyanobakteriyel suşların, rizosfer izolatlarının \% 80'ini oluşturduğunu belirlemişlerdir. Ayrica Hapalosiphon intricatus West \& G.S. West, Westiellopsis sp. Janet, ve Calothrix ghosei Bharadwaja, rizosferden izole edilen diğer türler olarak kaydedilmiştir (Prasanna et al., 2009a). Oscillatoria Vaucher ex Gomont ve Phormidium Kützing ex Gomont'un rizosferde bulunduğu, Scytonema C. Agardh ex É. Bornet \& C. Flahault'nın ise tuzlu toprak örneklerinde baskın olduğu belirlenmiştir. Song, Martensson, Eriksson, Zheng ve Rasmussen, (2005) Çin'deki pirinç tarlalarında siyanobakterilerin çeşitliliğini değerlendirmişler, Nostoc ve Phormidium dahil olmak üzere 24 tip tespit etmişlerdir. Benzer bir dağılım İran'ın pirinç ekili bölgelerinden elde edilmiş (Shariatmadari, Riahi, Hastroudi, Ghassempour, \& Aghashariatmadar, 2013) ve 20 lokasyondan 49 farklı tür izole edilmiştir. Bu taksonlar arasında, Anabaena ve Nostoc çoğu istasyonda baskın olarak bulunmuştur (Shariatmadari et al., 2013).

Calothrix ghosei Bharadwaja, Hapalosiphon intricatus West \& G.S.West, Nostoc sp. Vaucher ex Bornet \& Flahault, Hapalosiphon sp. Nägeli ex É.Bornet \& C.Flahault, Calothrix sp. C. Agardh ex Bornet \& Flahault, Desmonostoc muscorum (C.Agardh ex Bornet \& Flahault) Hrouzek \& Ventura, Westiellopsis prolifica Janet, Calothrix membranacea Schmidle, olarak tanımlanan sekiz farklı cinse ait sekiz siyanobakteri türü izole edilmiştir. Pirinç tarlalarının siyanobakteriyal çeşitliliği ile ilgili yapılan çalışmada, Phormidium ile birlikte, Nostoc ve Anabaena' nın baskın olduğu saptanmış 
ve bu türler oldukça rekabetçi olarak tanımlanmıştır (Yadav et al., 2017). Nostoc'un, serbest yaşayan ve çok çeşitli bitki türleriyle simbiyotik ortaklık kuran çok yönlü diazotrofik siyanobakteriyel cinslerden biri olduğu bilinmektedir. Bu cinsin üyelerinin, çeşitli ekolojik habitatlara uyum sağlayan özellik gösterdiği saptanmıştır (Prasanna et al., 2009b).

Siyanobakterilerin çevrelerine çok sayıda metabolit salgıladıkları bilinmektedir; bu da yakın çevrelerinde bulunan diğer organizmaların büyümesini ve gelişmesini etkileyebilir. Pirinç fideleri algal filtratla muamele edilmiş, gelişme sonunda köklerde algler tarafından salgılanan gibberalik asit benzeri bir bileşik tespit edilmiştir (Singh, Prabha, Yandigeri, \& Arora, 2011). Çeltik tarlalarından izole edilen $D$. muscorum'dan üretilen bir maddenin kromatografi tanımlaması yapılmış, bu madde indol asetik aside benzer özelliklere göstermiştir (Prasanna et al., 2009a). Daha sonra Misra \& Kaushik (1989a; 1989b) tarafından yapılan çalışmalarda; Hapalosiphon pumilus Kirchner ex Bornet \& Flahault ve D. muscorum'un hücre ve hücre dışı bileşiklerinin çeltik fidelerinin uzunluğu ve gelişiminin kontrol fidelerine göre önemli oranda arttırdığını saptamışlardır. Çimlenme oranı, sürgün ve kök uzunluğu, biyokütle gibi gelişme özelliklerindeki artışın, bitkinin çeşitli fitokimyasal bileşenlerindeki artış ile pozitif ilişkili olduğu gösterilmiştir.

Nostoc oryzae (F. E. Fritsch) J. Komárek \& K. Anagnostidis, Trichormus doliolum (Bharadwaja) Komárek \& Anagnostidis, Phormidium sp., Calothrix geitonos Skuja, Hapalosiphon intricatus, Trichormus fertilissimus (C. B. Rao) Komárek \& Anagnostidis, Tolypothrix tenuis Kützing ex Bornet \& Flahault, Oscillatoria acula Brühl \& Biswas ve Leptolyngbya boryana (Gomont) Anagnostidis \& Komárek gibi siyanobakteriyel suşlar ile aşılanan çeltikte; fenolik asitlerin (gallik, gentisic, caffeic, chlorogenic) flavonoidler (rutin ve quercetin) fitohormonlarin (indol asetik asit ve indol bütirik asit), yapraklarda ise protein ve klorofil içeriğinde artış olduğu yapılan çalışmada belirtilmiştir (Singh et al., 2011). L. boryana ve O. acula ile aşılanmış çeltik yapraklarında peroksidaz ve fenilalanin amonyak liyaz enzim aktivitesi ve toplam fenolik içeriğinin yükseldiği rapor edilmiştir (Singh et al., 2011).

Siyanobakteriler tarafından üretilen biyoaktif bileşiklerin, bitkinin toprak altı ve toprak üstü kısımlarının gelişimini tetiklemekten sorumlu olan fitohormon düzeylerini arttırdığı saptanmıştır. Fitohormonların ayrıca, enzimatik aktiviteleri ve bitki büyümesi sırasında meydana gelen metabolik değişiklikleri düzenlediği bilinmektedir (Tvorogova, Osipora, Doduyeva, \& Lutova, 2013) ve bu nedenle, savunma enzimlerinden peroksidaz ve fenillalanin amonyak ligaz enzimlerinin aktivitesindeki artış da fitohormon düzeylerine bağlanmıştır (Tvorogova et al., 2013). Flavonoidler ve fitohormonların bitkimikroorganizma etkileşimlerine yardımcı oldukları rapor edilmiştir (Jaiswal, Das, Koli, \& Pabbi, 2018), bu bileşikler mikroorganizmaların kök kolonizasyonunu arttırmış (Kehr, Picchi, \& Dittmann, 2011), diğer organizmaların popülasyonu üzerinde allelokimyasal etkiyi sağlamıştır (Khan, Syeed, Nazar, R., \& Anjum, 2012). Bunlar aynı zamanda sinyal moleküller olarak görev yapmıştır (Kehr et al., 2011; Khan et al., 2012).

\section{Siyanobakterilerin Biyotik ve Abiyotik Stresle Mücadeledeki Rollerinin Önemi}

4.1. Siyanobakterilerin Tuza Toleransı
Siyanobakteriler, tuzdan etkilenen topraklarda doğal olarak koloni oluşturduklarından genellikle tuz stresine karşı toleranslı kabul edilmiştir. Siyanobakterilerin tuzlu topraklarda oluşturduğu kolonilerin rizosfer tarafından toprağa çeşitli metabolitlerin salınımını sağladığı ve bu metabolitlerin de bitki büyüme-gelişmesini teşvik ettiği yapılan çalışmalar ile belirlenmiştir. (Sing \& Dhar, 2010). Scytonema hofmanii C. Agardh ex Bornet \& Flahault 'nin tuz stresine maruz alanlarda yetiştirilen pirinç fidelerinin gelişimi üzerinde olumlu bir etkisi olduğu bulunmuştur (Rodriguez et al., 2006). Tamoi, Kurotaki, \& Fukamizo (2007) tarafından Synechocystis'ten Ssglc olarak adlandirılan ve $\beta$-1,4-glukonaz benzeri bir proteini (SsGlc) kodlayan bir gen izole edilmiştir. Bu genin tuz stres toleransında işlev gördüğü ve dolayısıyla bitkilerde tuz toleransını arttırmak için kullanılabileceği tespit edilmiştir.

\subsection{Siyanobakterilerin Hastalıklara Karşı Direnci}

Toprak kaynaklı bitki patojenlerine karşı kullanılacak biyokontrol etmenleri olarak bitki gelişimini teşvik eden bakterilerin kullanımı, sürdürülebilir bir tarım için son yıllarda oldukça cazip hale gelmiştir. Bu mikroorganizmalar, hücre duvarının fiziksel ve mekanik gücünü güçlendiren ve patojenlere karşı savunma için metabolitlerin sentezi ile konakçının fizyolojik ve biyokimyasal reaksiyonunu değiştiren indüklenmiş sistemik direncini (ISR) ortaya çıkarmaktadır (Chaudhary et al., 2012).

Bazı siyanobakterilerin, bitki patojenlerinin hastalık oluşumunu azalttığı tespit edilmiştir (Tablo 1). Örneğin; Calothrix elenkinii Kossinskaja'nin kültür filtratı ve etil asetat ekstresinin; saksı denemelerinde, Pythium aphanidermatum (Edson) Fitzp ile enfekteli soya fasulyesi, domates, biber tohumları üzerinde hastalık şiddetini azalttığ1 bulunmuştur (Manjunath et al., 2010). Pythium debaryanum R. Hesse, Fusarium oxysporum f.sp. lycopersici W.C. Snyder \& H.N. Hansen, Gibberella fujikuroi (Sawada) Wollenw, ve Rhizoctonia solani J.G. Kühn'yi içeren bir grup fungal patojenler ile inokule edilmiş domates fidelerinde çökerten hastalığının Trichormus variabilis (Kützing ex Bornet \& Flahault) Komarek \& Anagnostidis ve Anabaena oscillarioides Bory ex Bornet \& Flahault uygulamaları ile azaldığı incelenmiştir (Chaudhary et al., 2012). Trichormus variabilis ve $A$. laxa A.Braun 'nın, Fusarium sp. solgunluğuyla mücadele edilen domates bitkilerinde sistemik savunma yanıtı oluşturduğu bulunmuştur. Fenilalanin amonyak liyaz (PAL), polifenol oksidaz (PPO), kitosanaz ve $\beta-1,3$ glukanaz gibi enzim aktiviteleri, siyanobakteriyal formülasyonlarla muamele edilen domates fidelerinin köklerinde yüksek bulunmuştur. Bu durum domates fideleri ile siyanobakteriyal etkileşimin önemini ortaya koymuştur (Prasanna et al., 2013).

\subsection{Siyanobakterilerin Sinyal Molekülleri}

Fitohormonlar; rizosferik, epifitik ve simbiyotik mikroorganizmalar tarafından salgılanmaktadır (Shan et al., 2012). Bitkilerle ilişkili mikroorganizmalar tarafından üretilen fitohormonlar, bitki büyümesinin uyarılmasında, bitki patojenezinde ve bitki-mikroorganizma simbiyotik etkileşimlerinde belirleyiciler olarak anahtar rol oynamaktadır (Singh, 2014). Bu hormonlar, konakçının endojen fitohormon dengesini değiştirebilir ve tepkilerini tetikleyebilir, bu durumun üretilen fitohormon konsantrasyonuna, konakçının tipine ve hormonlara olan duyarlılığına bağlı olduğu açıklanmıştır (Sokolova et al., 
2011). Fitohormonlar, bitkilerde çeşitli fizyolojik süreçlerin koordine edilmesine katkıda bulunurlar. Bunların tohum çimlenmesinin düzenlenmesi, kök oluşumu, çiçeklenme, dal oluşumu ve meyve olgunlaşmasında önemli etkileri belirlenmiştir (McAtee, Karim, Schaffer, \& David, 2013). Ayrıca çevresel faktörlere karşı bitki direncini arttırmışlar, genlerin ekspresyonu, enzimlerin, pigmentlerin ve metabolitlerin sentezini indüklemişlerdir (Shan et al.,
2012). Yapılan çalışmalar, siyanobakterilerin, IAA (indol3-asetik asit), sitokinin, gibberellin, etilen, jasmonik asit veya absisik asitlere benzer büyümeyi arttırıcı düzenleyiciler üreterek bitkilere yararlı olabildiğini göstermiştir (Kher et al., 2011; Moreno, Blanch, \& del Castillo, 2010; Osman et al., 2010). Tablo 2'de baz1 siyanobakter tarafından üretilen bitki gelişimini destekleyen hormonlar verilmiştir.

Tablo 1. Farklı siyanobakterilerin bazı bitki patojenlerine karşı biyokontrolü

\begin{tabular}{|c|c|c|c|c|}
\hline Siyanobakteri & Hedef organizma & Bitki & Hastalık & Kaynak \\
\hline \multirow{3}{*}{ Anabaena sp. } & \multirow{3}{*}{$\begin{array}{l}\text { Pythium debaryanum R. Hesse } \\
\text { Fusarium verticillioides (Sacc.) Nirenberg } \\
\text { F. oxysporum f.sp. lycopersici W.C. Snyder \& } \\
\text { H.N. Hansen }\end{array}$} & Domates & Çökerten & \multirow{3}{*}{ Chaudhary et al. (2012) } \\
\hline & & Domates & Kök ve kök boğazı çürüklüğü & \\
\hline & & Domates & Solgunluk & \\
\hline $\begin{array}{l}\text { Nostoc commune Vaucher ex } \\
\text { Bornet \& Flahault FA } 103\end{array}$ & $\begin{array}{l}\text { F.oxysporum f.sp. lycopersici W.C. Snyder \& } \\
\text { H.N. Hansen }\end{array}$ & Domates & Solgunluk & Kim \& Kim (2008) \\
\hline $\begin{array}{l}\text { Oscillatoria spp. } \\
\text { Anabaena sp., }\end{array}$ & & & & \\
\hline $\begin{array}{l}\text { Nostoc sp., } \\
\text { Nodularia sp. Mertens ex } \\
\text { Bornet \& Flahault, } \\
\text { Calothrix sp. }\end{array}$ & Alternaria alternata (Fr.) Keissl. & Pirinç & Yaprak leke hastalığı & Kim (2006) \\
\hline Nostoc commune FK-103 & & & & \\
\hline $\begin{array}{l}\text { Oscillatoria tenuis C.Agardh } \\
\text { ex Gomont FK109 }\end{array}$ & Phytophthora capsici Leonian & Pirinç & Kök boğazı yanıklığ1 & Kim (2006) \\
\hline
\end{tabular}

Tablo 2. Farklı siyanobakteri tarafından üretilen bazı bitki gelişimini teşvik eden hormonlar

\begin{tabular}{|c|c|c|c|}
\hline Siyanobakteri & Grup & Hormon & Kaynak \\
\hline $\begin{array}{l}\text { Calothrix spp., } \\
\text { Kamptonema animale (C.Agardh ex Gomont) } \\
\text { Strunecký, Komárek \& J.Smarda }\end{array}$ & Cyanophyta & Oksin, sitokinin, kinetin benzeri aktivite & Osman et al. (2010) \\
\hline Nostoc spp. & Cyanophyta & İndol-3-asetik asit & Shariatmadari et al. (2013) \\
\hline Aphanothece sp. C.Nägeli MBDU515 & Cyanophyta & İndol-3-asetik asit & Rodriguez et al. (2006) \\
\hline $\begin{array}{l}\text { Wollea vaginicola (F.E.Fritsch \& Rich) R.N.Singh, } \\
\text { Nostoc calcicola Brébisson ex Bornet \& Flahault }\end{array}$ & Cyanophyta & $\begin{array}{l}\text { Indol-3-asetik asit, indol-bütirik asit, indol-3- } \\
\text { propionik asit }\end{array}$ & Khan et al. (2012) \\
\hline Tetradesmus obliquus (Turpin) M.J.Wynne & Cyanophyta & İndol-3-asetik asit & Khan et al. (2012) \\
\hline Chroococcus, Nostoc, Phormidum & Cyanophyta & Sitokinin & Zizkova et al. (2017) \\
\hline
\end{tabular}

Misra ve Kaushik, (1989a), siyanobakterilerin fitohormona benzer özellikte hormonal bileşikler ürettikleri belirlemişlerdir. Yaptıkları araştırmada Nostoc and Haplosiphon' un ekstraktlarının oksin benzeri özellikte olup, ekstraktların saflaştırılması sonucunda indol 3 asetik asit, indol-3-propionik asit ve 3-metil indol özelliğinde olduğu tespit edilmiştir (Misra \& Kaushik, 1989a). Shariatmadari et al. (2013) Anabaena, Anabaenopsis V. V. Miller, Calothrix, Chlorogloeopsis A. K. Mitra \& D.C. Pandey, Cylindrospermum Kützing ex É. Bornet \& C. Flahault, Gloeothece C. Nägeli, Nostoc, Plectonema Thuret ex Gomont, Haplosiphon ve Synechocystis'in IAA ürettiği saptamışlardır. IAA biyosentezinde önemli bir gen olan ipdC geninin homologları ise siyanobakterilerin bazı suşlarında tanımlamışlardır.

Karthikeyan et al. (2009) tarafından yapılan araştırmada; karanlık ve 1şık alan koşullar altında Calothrix sp., Calothrix ghosei, Calothrix membranacea Schmidle, Hapalosiphon intricatus, Nostoc sp., D. muscorum, Westiellopsis prolifica gibi siyanobakteriyel suşlar tarafından üretilen IAA miktarı araştırılmış; karanlıkta inkübe edilen kültür ekstraktlarında IAA miktarı 0.6-3.37 $\mu \mathrm{g} / \mathrm{ml}$ arasında, 1şıkta ise IAA miktarını $0.5-1.39 \mu \mathrm{g} / \mathrm{ml}$ olarak bulmuşlardır. Bitki büyümesini hızlandıran sitokinin ve indol-3-asetik asit (IAA), Anabaena, Oscillatoria, Phormidium, Chroococcidiopsis Geitler, Synechocystis gibi siyanobakteriyel suşlarda Hussain et al. (2013) tarafından saptanmıştır. Yapılan araştırmada Siyanobakteriyel suşlar kültür ortamında transzeatin, ciszeatin, zeatin ribosid, dihidrozeatin ribosid ve zeatin-oglukozit olmak üzere beş farklı sitokinin salgılayabildiği belirlenmiştir (Hussain et al., 2013). Chroococcidiopsis sp. diğer siyanobakteriler ile karşılaştırıldığında en yüksek sitokinin üreticisi olarak kabul edilmiş, Nostoc paludosum Kützing ex Bornet \& Flahault, Lyngbya, Chlorogloeopsis ve Calothrix'in de sitokin ürettiği tespit edilmiştir (Osman et al., 2010).

Hussain et al. (2013) tarafından pirinç köklerinden izole edilen endofitik Nostoc kültüründe sitokinin ve IAA belirlenmiştir. Sera koşullarında bu Nostoc suşunun, buğday ve pirinç fideleri ile muamelesi sonunda buğday ve pirinç sürgün uzunluğu, kök uzunluğu ve tane ağırlığında artış olduğu saptanmıştır. Siyanobakteriyel suşların lateral kök oluşumunu tetiklediği, siyanobakterilerle aşılı bitki köklerinin, yüzey alanlarının artmasına neden olduğu ve siyanobakteriler tarafından salınan fitohormonların, bitki kökleri ile siyanobakteri birlikteliğinde çok önemli bir rol oynadığı açıklanmıştır (Hussain et al., 2013). Gibberellin benzeri maddeler de Jaaginema angustissimum (West \& G.S.West) Anagnostidis \& Komárek, Cylindrospermum sp., Anabaenopsis sp.'den de izole edilmiştir (Osman et al., 2010).

Siyanobakterilerde jasmonik asit (JA) varlığı tespit edilmiştir (Singh, 2014). Bu bakterilerin solgunluk, su stresi, ozmotik stres ve tuz stresi gibi stres koşullarında bitkinin hayatta kalmasını sağlayan absisik asit birikimini tetiklediği bildirilmiştir (Khan et al., 2012). Jasmonik asit ve çeşitli metabolitlerinin bitki gelişiminin yanı sıra 
abiyotik ve biyotik strese karşı bitki reaksiyonlarını düzenlemekten sorumlu olduğu bilinmektedir (Khan et al., 2012). Siyanobakterilerde jasmonik asit (JA) tespit edilmiştir (Singh, 2014). Ayrica Synechococcus, Anabaena, Nostoc, Calothrix, Scytonema ve Cylindrospermum üyelerinin etilen ürettikleri bildirilmiştir (Singh et al., 2016).

\subsection{Siyanobakteriyel Polisakkaritler}

Polisakkaritler, bitki bağışıklığı indükleyicilerinin en önemlilerinden biridir (Singh, 2014). $\beta$-glukanlar, kitin, lipopolisakkaritler gibi polisakkaritlerin çoğu, bakteriyel ve fungal türlerden salınırken, konakçı bitkilerle etkileşimlidir. Bununla birlikte, algler tarafından üretilen polisakkaritlerin, bitkileri patojenlere karşı koruyabileceği ve böylece biyolojik olarak aktif moleküllerin salgılanacaği ucuz bir kaynak olarak açıklanmıştır (Singh, 2014).

Siyanobakteriyel polisakkaridlerin polisakkarit kaynağı olarak kullanımı ile ilgili çalışmalar oldukça azdır. Siyanobakteriyel polisakkaritler, hücre etrafında musilaj bir dış tabaka olarak bulunmaktadırlar. Bir kılıf veya hücre yüzeyi ile yakından ilişkili olan bir kapsül ya da sadece hücre yüzeyi veya çözünür polisakkaridler ile gevşek bir şekilde ilişkili olan bir yapı olarak bulunurlar. Hücre büyümesi sırasında çevreye salınırlar. Bu ekzopolisakkaritlerin, bir sınır tabakası olarak hücrenin korunmasında önemli rol oynadıkları bildirilmiştir (Singh et al., 2016), topraktaki sodyum iyonlarını (Öztürk \& Aslim, 2010) ve ağır metalleri (De Philippis, Colica, \& Micheletti, 2011) bağladıkları, yapışma özelliklerinden dolayı toprak agregasyonuna katk1 sağladıkları saptanmıştır (de Caire, de Cano, de Mule, Palma, \& Colombo, 1997).

$\mathrm{Xu}$ et al. (2013) tarafından Leptolyngbya tenuis (Gomont) Anagnostidis \& Komárek'den salınan bir polisakkarit, çalı bitkisi olan Caragana korshinskii Kom.'nin bitki büyümesini arttırdığı belirlenmiştir. Polisakkaridin ortama eklenmesi, tohum çimlenme oranını, iyon alımını, fotosentez aktivitesini ve karbonhidrat içeriğini de önemli ölçüde arttırdığı görülmüştür. Ayrıca, süperoksit dismutaz üreterek, stres sirasında organizmalarda reaktif oksijen türü oluşumunu ortadan kaldırmaktan sorumlu olarak oksidatif hasarın azaltılmasını sağlamıştır. Bu polisakkaritler galaktoz, fruktoz, ksiloz ve birkaç tanımlanmamış şekerlerden oluşmaktadır. Polisakkarit içeren Desmonostoc muscorum ve Hapalosiphon pumilus Kirchner ex Bornet \& Flahault ekstraktlarının, çeltik fidelerinin çimlenmesini uyardığı ve böylece fide büyümesini geliştirdiği belirlenmiştir (Misra \& Kaushik, 1989a). Siyanobakteriler tarafindan salınan polisakkaritlerin, 6-10 farklı monosakkaritten oluşan karmaşık heteropolimerler olduğu, çoğunun piruvil veya sülfat gibi üronik asitlerin veya değişik grupların varlığından dolayı anyonik bir yapı gösterdiği bildirilmiştir. Siyanobakteriyel EPS'lerdeki 10 monosakkari ise; heksozlardan glukoz, galaktoz ve manoz, pentozlardan riboz, arabinoz ve ksiloz, deoksiheksozlardan fukoz ve ramnoz ile asidik hekzos olan glukuronik ve galakturonik asit olarak saptanmıştır (Pereira et al., 2009). Bitkilerde patojenle ilişkili moleküler paternler (PAMP) olarak işlev gören, bağışıklık indükleyicileri olduğu bilinen bir diğer polisakkarit grubu lipopolisakkaritler (LPS)'dir (Singh, 2014). Siyanobakteriyal LPS'ler ile ilgili yapılan çalışmalar oldukça sınırlıdır.

\subsection{Siyanobakteriyel Vitaminler ve Pigmentler}

Vitaminlerin, bitkilerin büyümelerine ve gelişimlerine yardımcı oldukları kanıtlanmıştır. Vitaminler, genel stresin azaltılmasına ve bitkilerin çeşitli enzimatik yollarını aktive ederek, hastalığa ve ekstrem koşullara karşı bağışıklıklarının artmasına yardımcı olurlar (Goyer, 2010). Tiamin (B1 vitamini); arpa ve bezelyede yaprak biti enfeksiyonlarını azaltmış (Hamada \& Jonsson, 2013), pirinç (Oryza sativa L.), tütün (Nicotiana tabacum L.), domates (Solanum lycopersicum L.), salatalıkta (Cucumis sativus L.) SAR (sistemik kazanılmış direnç) ile ilişkili genleri aktive ederek mantar, bakteri ve viral enfeksiyonların neden olduğu çeşitli hastalıklara karşı bitkileri koruduğu Lugtenberg \& Kamilova (2009) tarafından belirlenmiştir. Büyümeyi hızlandıran özelliği nedeniyle; tiamin, doku kültürü ortamının önemli bir bileşenidir (George, Hall, \& De Klerk, 2008). Bitki büyümesini önemli ölçüde uyarabilen toprak mikroorganizmalarının, çevrelerindeki vitaminleri serbest bıraktığı bildirilmiştir (Lugtenberg \& Kamilova, 2009).

Suda çözünen vitaminler, bitkilerin ve toprak mikroorganizmalarının gelişiminin uyarılmasında diğer biyolojik olarak aktif maddelerle sinerjik olarak etki edebilirler (Singh, 2014). Toprak mikroorganizmalarının çoğunun, biyotin, tiamin, kobalamin, pantotenik asit ve niasin gibi B-grubu vitaminleri ürettiği ve üretilen vitaminlerin bitki gelişimi için yararlı olduğu açıklanmıştır (Gupta, Ratha, Sood, Chaudhary, \& Prasanna, 2013).

Siyanobakterilerin de vitamin bakımindan zengin oldukları bilinmektedir. Spirulina Turpin ex Gomont, Anabaena sp., Dolichospermum flosaquae (Brébisson ex Bornet \& Flahault) P.Wacklin, L.Hoffmann \& J.Komárek, Dolichospermum circinale (Rabenhorst ex Bornet \& Flahault) P. Wacklin, L. Hoffmann \& J. Komárek, Microcystis pulverea (H. C. Wood) Forti, Nostoc sp., Nostoc punctiforme Hariot, Nodosilinea bijugata (Kongisser) Perkerson \& Kovácik, Kamptonema jasorvense (Vouk) Strunecký, Komárek \& J. Smarda ve Chroococcus minutus (Kützing) Nägeli gibi siyanobakteriyel türlerin; thiamine (vitamin B1), riboflavin (vitamin B2), folik asit, askorbik asit, nikotinik asit (vitamin B3), siyanokobalamin (vitamin B12) ve pentoten içerdiği rapor edilmiştir (Singh et al., 2016). Spirulina'nın B12 vitaminine ilave olarak B1, B2, B3 ve E vitaminlerini de içerdiği açıklanmıştır (Gupta et al., 2013). Vitamin $B_{12}$ (siyanokabalamin) siyanobakteriler tarafından üretilen en önemli vitamindir. Vitamin B12 (siyanokobalamin) Anabaena cylindrica Lemmermann, Nostoc cycadae Maruyama \& Fukushima, nom. inval., Cyanobium waterburyi Komárek ve Synechococcus suşlarında da tespit edilmiştir (Singh et al., 2016). D. muscorum and Hapalosiphon'dan elde edilen ekstraktların çeltiğin çimlenmesi ve bitki boyunu ticari vitaminlerle benzer oranda arttırdığı belirlenmiştir. D. muscorum ve Hapalosiphon'dan elde edilen ekstraktların kimyasal karakterizasyonu yapılmış ve bu iki suşun ekstraktlarında suda çözünen B-kompleksi grubu niasin, pantotenik asit, folik asit ve siyanokobalamin vitaminlerinin varlığını ortaya konulmuştur (Misra \& Kaushik, 1989b). Bu nedenle, ekim alanlarında bulunan siyanobakteriyel suşların bitkilere başlıca vitamin kaynağı olarak kullanılabileceği sonucuna ulaşılmıştır.

Polipeptitler ve peptitler, bitki savunmasını tetikleyen önemli sinyal moleküllerin bir grubudur (Yamaguchi \& Huffaker, 2011). Siyanobakteriyel sekonder 
metabolitlerin önemli bir kısmı, yüksek düzeyde yapısal varyasyona sahip peptitlerdir veya peptidik alt yapılara sahiptir. Bu peptidlerin çoğunun NRPS (nonribosomal peptit sentetaz) veya NRPS/PKS (poliketid sintaz) hibrid yolakları ile sentezlendiği varsayılmakta ve bugüne kadar 600 siyanobakteriyel peptit tanımlanmıştır (Kehr et al., 2011). Bu peptitlerin veya bunları oluşturan aminoasitlerinin birçoğu bitki büyümesini ve gelişimini desteklemekten sorumlu olarak belirlenmiştir. Kehr et al. (2011), D.muscorum'un kültür filtratındaki amino asitler ve peptidlerin bitkilerin gelişmesini desteklediği sonucuna varmıştır. Benzer olarak D. muscorum, $H$. pumilus ve Cylindrospermum muscicola Kützing ex Bornet \& Flahault'nın aminoasitlerce zengin olan kültür filtratlarının pirinç fidesinin gelişiminde uyarıcı etkiye sahip olduğu bildirilmiştir (Misra \& Kaushik, 1989a). D.muscorum için kaydedilen aminoasitler treonin, glutamik asit, prolin, valin, glisin/aspartik asit ve serin/arjinin olarak ve H.pumilus'da ise sistin, arjinin, serin, aspartik asit, glisin histidin, izolösin, lisin ve ornitin/sistin olarak rapor edilmiştir (Misra \& Kaushik, 1989a). C. muscicola ekstraktında bulunan amino asitler, sistin, tirosin ve fenilalanin olarak belirlenmiş, pirinçte büyüme stimülasyonu için işlev gördüğü tespit edilmiştir (Misra \& Kaushik, 1989a). Karthikeyan et al. (2009) ise bitki büyümesini hızlandırabilen birkaç siyanobakteriyel türün (Nostoc sp., Hapalosiphon sp., Calothrix sp., W. prolifica) kültür ekstraktlarında hücre dışı proteinlerin varlığını saptamışlardır.

Siyanobakteriler klorofil a, karotenoidler ve fikobiliproteinler gibi zengin bir pigment kaynağıdır (Takaichi et al., 2009). Fikobiliproteinler (fikosiyanin, allosiyanin ve fikoeritrin) sadece siyanobakteriler ve kırmızı alglerde görülmüştür ve fikobiliproteinlerin toplam kuru ağırlığın yaklaşık \% 20'sini oluşturduğu belirlenmiştir (Singh, 2014). Arthrospira platensis Gomont'ten izole edilen mavi pigment olan fikosiyanin, sirasılyla Capsicum frutescens L. (kırmızı biber) ve Daucus carota L. (havuç) hücre kültürlerinde kapsaisin ve antosiyanin birikimini arttırmak için kullanılmıştır (Sing, 2014).

\section{Sonuç}

Günümüzde tarımsal ürünler için kullanılan kimyasalların azaltılması, kimyasalların yerine kullanılacak daha ekonomik bir ürün ve çevre dostu tarımın yapılmasına yardımcı olabilecek stratejiler talep edilmektedir. Ürün verimini arttırmak için çeşitli metodlar denenmektedir. Siyanobakteriler tarım alanlarında ve özellikle de çeltik yetiştirilen topraklarda bol miktarda bulunmakta olup, mikroalg ile birlikte toprağın mikrobiyal fotosentetik ajanları olarak kabul edilmektedir. Azot fiksasyonundaki önemli rolleri nedeniyle, siyanobakterilerin bitkisel üretimi arttırmak için tarımda kullanımı kaçınılmazdır. Azot fiksasyonu yetenekleri ile ilgili çeşitli araştırmalar olmasına rağmen, ekolojik rolleri tam olarak tanımlanmamıştır. Topraklardaki varlıkları, birçok sürecin işleyişi için büyük önem taşımaktadır. Tarım alanlarında siyanobakteriyel inokülasyonun, yüksek dozda azotlu gübrelerin varlığında bile verim artışı sağladığı belirlenmiştir. Bitkilerin azot içeriklerinin arttırmasının yanı sıra, siyanobakteriler bitki büyümesini teşvik için bir araç olarak kullanılabilirler. Bu nedenle birçok ülkede siyanobakteriyal içerikli biyogübrelerin geliştirilmesi ve uygulanmasında son yıllarda önemli ilerlemeler kaydedilmiştir.
Fitohormonların, polisakkaritlerin, vitaminlerin, aminoasitlerin ve peptitlerin biyosentezi, bitki büyümesi ve gelişimi için çok önemli olarak kabul edilmektedir. Bu aktif bileşikleri mikroorganizmalar rizosferde bitki köklerinin emebileceği yerlere serbest birakırlar.

Siyanobakteriyal suşların bitkinin büyümesini destekleyici aktivitesi yapılan çalışmalarda genellikle sera ve kontrollü koşullar altındagerçekleştirilen saksı denemeleri ile tespit edilmiştir. Siyanobakteriyel suşların tarla koşullarında da denenmesi için yeni çalışmalara gereksinim vardır. Derlememizin bu popülasyon dinamiklerinin daha detaylı araştırılması ve bu mikroorganizmaların tarım alanlarına uygulanması yönünde yaplacak çalışmalara 1şı tutması beklenmektedir.

\section{Kaynaklar}

Abdel-Raouf, N., Al-Homaidan, A.A., \& Ibraheem, I.B.M. (2012). Agricultural importance of algae. African Journal of Biotechnology, 11, 11648-11658.

Aguiar, R., Fiore, M.F., Franco, M.W., Ventrella, M.C., Lorenzi, A.S., Vanetti, C. A., \& Alfenas, A.C. (2008). A novel epiphytic cyanobacterial species from the genus Brasilonema causin damage to Eucalyptus leaves. Journal of Phycology, 44, 1322-1334.

Berendsen, R.L., Pieterse, C.M.J., \& Bakker, P. (2012). The rhizosphere microbiome and plant health. Trends Plant Science, 17, 478-486.

Boopathi, T., Balamurugan, V., Gopinath, S., \& Sundararaman, M. (2013). Characterization of IAA production by the mangrove cyanobacterium Phormidium sp. MI405019 and its influence on tobacco seed germination and organogenesis. Journal of Plant Growth, 32, 758-766.

Briceno, Z., Almagro, L., Sabater-Jara, A.B., Calderø, A.A., Pedreno, M.A., \& Ferrer, M.A. (2012). Enhancement of phytosterols, taraxasterol and induction of extracellular pathogenesis-related proteins in cell cultures of Solanum lycopersicum cv. MicroTom elicited with cyclodextrins and methyl jasmonate. Journal of Plant Physiology, 169, 1050-1058.

Chaudhary, V., Prasanna, R., Nain, L., Dubey, S.C., Gupta, V., Singh, R., ... Bhatnagar, A.K. (2012). Bioefficacy of novel cyanobacteria-amended formulations in suppressing damping off disease in tomato seedlings. World Journal of Microbiology \& Biotechnology, 28, 3301-3310.

de Caire ,G., de Cano, S.M., de Mule, M.C.Z., Palma, R.M., \& Colombo, K. (1997). Exopolysaccharides of Desmonostoc muscorum Ag. (Cyanobacteria) in the aggregation of soil particles. Journal of Applied Phycology, 9, 249-253.

De Philippis, R., Colica, G., \& Micheletti, E. (2011). Exopolysaccharideproducing cyanobacteria in heavy metal removal from water: molecular basis and practical applicability of the biosorption process. Applied Microbiology \& Biotechnology, 92, 697-708.

George, E.F., Hall, M.A., \& De Klerk, G.J. (2008). The components of plant tissue culture media II: organic additions, osmotic and $\mathrm{pH}$ effects, and support systems. In PlantPropagation by TissueCulture (eds:George,E.F.,Hall, M.A., De Klerk, G.) Dordrecht: Springer Press. 119 pp.

Goyer, A. (2010). Thiamine in plants: aspects of its metabolism and functions. Phytochemistry, 71, 1615-1624.

Gupta, V., Ratha, S.K., Sood, A., Chaudhary, V., \& Prasanna, R. (2013). New insights into the biodiversity and applications of cyanobacteria (bluegreen algae)-Prospects and challenges. Algal Research, 2, 79-97.

Hamada, A.M. \& Jonsson, L.M.V. (2013). Thiamine treatments alleviate aphid infestations in barley and pea. Phytochemistry, 94, 135-141.

Hussain, A, Hamayun, M., \& Shah, S.T. (2013). Root colonization and phytostimulation by phytohormones producing entophytic Nostoc sp. AH-12. Current Microbiology, 67, 624-630

Jaiswal, A., Das, K., Koli, D.K., \& Pabbi, S. (2018). Characterization of cyanobacteria for IAA and siderophore production and their effect on rice seed germination. International Journal of Current Microbiology Applied Science, 7, 5212-5222.

Karthikeyan, N., Prasanna, R., Sood, A., Jaiswal, P., Nayak, S., \& Kaushik, B.D. (2009). Physiological characterization and electron microscopic investigations of cyanobacteria associated with wheat rhizosphere. Folia Microbioogy, 54, 43-51.

Kehr, J., Picchi, D.G., \& Dittmann, E. (2011). Natural product biosyntheses in cyanobacteria: a treasure trove of unique enzymes. Beilstein Journal of Organic Chemistry, 7, 1622-1635. 
Khan, M.I.R., Syeed, S., Nazar, R., \& Anjum, N.A. (2012). An insight into the role of salicylic acid and jasmonic acid in salt stress tolerance. In Phytohormones and Abiotic Stress Tolerance in Plants (eds: Khan NA, Nazar R, Iqbal N, Anjum NA.) Berlin, Heidelberg: Springer. 300 pp.

Kim, J.D. (2006). Screening of cyanobacteria (blue-green algae) from rice paddy soil for antifungal activity against plant pathogenic fungi. Mycobiology, 34, 138-142.

Kim, J., \& Kim, J.D. (2008). Inhibitory effect of algal extracts on mycelial growth of the tomato-wilt pathogen, Fusariumoxysporum f. sp. lycopersici. Mycobiology, 36, 242-248.

Long, S.R. (2001). Genes and signals in the Rhizobium-legume symbiosis. Plant Physiology, 125, 69-72.

Lugtenberg, B., \& Kamilova, F. (2009). Plant-growth- promoting rhizobacteria. Annual Review Microbiology, 63, 541-556.

Magnuson, A. (2019). Heterocyst Thylakoid Bioenergetics. Life, 9, 13.

Manjunath, M., Prasanna, R., Nain, L., Dureja, P., Singh, R., Kumar, A., ..., \& Kaushik, B.D. (2010). Biocontrol potential of cyanobacterial metabolites against damping off disease caused by Pythium aphanidermatum in solanaceous vegetables. Archieve Phytopathology and Plant Protection, 43, 666-677.

McAtee, P., Karim, S., Schaffer, R., \& David, K. (2013). A dynamic interplay between phytohormones is required for fruit development, maturation, and ripening. Front Plant Sciences, 4,1-7.

Mendes, R., Garbeva, P., \& Raaijmakers, J.M. (2013). The rhizosphere microbiome: significance of plant beneficial, plant pathogenic, and human pathogenic microorganisms. FEMS Microbiology Reviews, 37, 634-663.

Misra, S., \& Kaushik, B.D. (1989a). Growth promoting substances of Cyanobacteria. II. Detection of amino acids, sugars and auxins. Proceedings of the National Academy of Sciences, India Section B, 55, 499_ 504

Misra, S., \& Kaushik, B.D. (1989b). Growth promoting substances of Cyanobacteria. I. Vitamin and their influence on rice plant. Proceedings of the National Academy of Sciences, India Section B, 55, 295-300.

Moreno, F.D., Blanch, G.P., \& del Castillo, M.L.R. (2010). Methyl jasmonate-induced bioformation of myricetin, quercetin and kaempferol in red raspberries. Journal of Agricultural and Food Chemistry, 58, 11639-11644.

Nagarajan, M., Maruthanayagam, V., \& Sundararaman, M. (2011). A review of pharmacological and toxicological potentials of marine cyanobacterial metabolites. Jourmal of Applied Toxicology, 32, 153-185.

Osman, M.E.H., El-Sheekh, M.M., El-Naggar, A.H., \& Gheda, S.F. (2010). Effect of two species of cyanobacteria as biofertilizers on some metabolic activities, growth, and yield of pea plant. Biology and Fertility of Soils, 46, 861-875.

Öztürk, S., \& Aslim, B. (2010). Modification of exopolysaccharide composition and production by three cyanobacterial isolates under salt stress. Environmental Science and Pollution Research, 17, 595-602.

Pan, Y.G., \& Liu, X.H. (2011). Effect of benzo-thiadiazole-7- carbothioic acid $S$-methyl ester (BTH) treatment on the resistant substance in postharvest mango fruits of different varieties. African Journal of Biotechnology, 10, 15521-15528.

Prasanna, R., Jaiswal, P., Nayak, S., Sood, A., \& Kaushik, B.D. (2009a). Cyanobacterial diversity in the rhizosphere of rice and its ecological significance. Indian Journal of Microbiology, 49, 89- 97.

Prasanna, R., Nain, L., Ancha, R., Srikrishna, J., Joshi, M., \& Kaushik, B.D. (2009b). Rhizosphere dynamics of inoculated cyanobacteria and their growth-promoting role in rice crop. Egypt Journal of Biology, 11, 26-36.

Prasanna, R., Sharma, E., Sharma, P., Kumar, A., Kumar, R., Gupta, V., ... \& Shivay, Y.S. (2013). Soil fertility and establishment potential of inoculated cyanobacteria in rice crop grown under non-flooded conditions. Paddy Water Environmental, 11, 175-183.

Pereira, S., Zille, A., Micheletti, E., Moradas-Ferreira, P., De Philippis, R., \& Tamagnini, P. (2009). Complexity of cyanobacterial exopolysaccharides: composition, structures, inducing factors and putative genes involved in their biosynthesis and assembly. FEMS Microbiological Reviews, 33, 917-941.

Rodriguez, A.A., Stella, A.M., Storni, M.M., Zulpa, G., \& Zaccaro, M.C. (2006). Effects of cyanobacterial extracellular products and gibberellic acid on salinity tolerance in Oryza sativa L. Saline Systems, 2, 7-10.

Shan, X., Yan, J., \& Xie, D. (2012). Comparison of phytohormone signaling mechanisms. Current Opinion Plant Biology, 15, 84-91.

Shariatmadari, Z., Riahi, H., Hastroudi, M.S., Ghassempour, A., \& Aghashariatmadary, Z. (2013). Plant growth promoting cyanobacteria and their distribution in terrestrial habitats of Iran. Soil Science Plant Nutrition, 59, 535-547.
Singh, J.S., Kumar, A., Rai, A.N., \& Singh, D.P. (2016). Cyanobacteria: A precious bioresource in agriculture, ecosystem and environmental sustainability. Frontiers in Microbiology, 7, 1-19.

Singh, S. (2014). A review on possible elicitor molecules of cyanobacteria: their role in improving plant growth and providing tolerance against biotic and abiotic stress. Journal of Applied Microbiology, 117, 1221-1244.

Singh, D.P., Prabha, R., Yandigeri, M.S., \& Arora, D.K. (2011). Cyanobacteria-mediated phenylpropanoids and phytohormones in rice (Oryza sativa) enhance plant growth and stress tolerance. Antonie Van Leeuwenhoek, 100, 557-568.

Singh, N.K., \& Dhar, D.W. (2010). Cyanobacterial reclamation of saltaffected soil. In Genetic Engineering, Biofertilisation, Soil Quality and Organic Farming Sustainable Agriculture Reviews. Vol: 4. Netherlands, Springer Publisher, 275 pp.

Sokolova, M.G., Akimova, G.P., \& Vaishlya, O.B. (2011). Effect of phytohormones synthesized by rhizosphere bacteria on plants. Applied Biochemistry and Microbiology, 47, 274-278.

Song, T., Martensson, L., Eriksson, T., Zheng, W., \& Rasmussen, U. (2005). Biodiversity and seasonal variation of the cyanobacterial assemblage in a rice paddy field in Fujian, China. FEMS Microbiol Ecology, 54, 131-140.

Stamm, P., \& Kumar, P.P. (2010). The phytohormone signal network regulating elongation growth during shade avoidance. Journal of Experimental Botany, 61, 2889-2903.

Takaichi, S., Maoka, T., \& Mochimaru, M. (2009). Unique Carotenoids in the terrestrial cyanobacterium Nostoc commune NIES-24: 2-hydroxymyxol 20-fucoside, nostoxanthin and canthaxanthin. Current Microbiology, 59, 413- 419.

Tamoi, M., Kurotaki, H., \& Fukamizo, T. (2007). b-1,4- Glucanase-like protein from the cyanobacterium Synechocystis PCC6803 is a b-1,3-1,4glucanase and functions in salt stress tolerance. Biochemistry Journal, 405, 139-146.

Tvorogova, V.Y., Osipova, M.A., Doduyeva, I.Y., \& Lutova, L.A. (2013). Interactions between transcription factors and phytohormones in the regulation of plant meristem activity. Russian Journal of Genetics, 3, 325337.

Willis, B.F., Rodrigues, B.F., \& Harris, P.J.C. (2013). The Ecology of arbuscular mycorrhizal fungi. Critical Reviews in Plant Sciences, 32, 1-20.

Xu, Y., Rossi, F., Colica, G., Deng, S., De Philippis, R., \& Chen, L. (2013). Use of cyanobacterial polysaccharides to promote shrub performances in desert soils: a potential approach for the restoration of desertified areas. Biology and Fertility Soils, 49, 143-152.

Yadav, S., Rai, S., Rai, R., Shankar, A., Singh, S. \& Rai, L.C.R. (2017) Cyanobacteria: Role in Agriculture, Environmental Sustainability, Biotechnological Potential and Agroecological Impact. Plant-Microbe Interactions in Agro-Ecological Perspectives, (Ed: Singh DP, Singh HB, Prabha R.) Microbial Interactions and Agro-Ecological Impacts, Vol. 2. Springer, $277 \mathrm{pp}$.

Yamaguchi, Y., \& Huffaker, A. (2011). Endogenous peptide elicitors in higher plants. Current Opinion Plant Biology, 14, 351-357.

Zizkova, E., Kubes, M., Dobrev, P.I., Pribyl, P., Simura, J., Zahajska, L., ... \& Motyka, V. (2016). Control of cytokinin and auxin homeostasis in cyanobacteria and algae. Annals of Botany, 119, 151-166. 